\title{
Neural Prosthesis
}

National Cancer Institute

\section{Source}

National Cancer Institute. Neural Prosthesis. NCI Thesaurus. Code C18130.

Medical devices which interact with or replace parts of the nervous system, e.g., cochlear implant. 